\title{
Frege's Puzzle for Perception
}

BOYD MILLAR

\begin{abstract}
According to an influential variety of the representational view of perceptual experiencethe singular content view - the contents of perceptual experiences include singular propositions partly composed of the particular physical object(s) a given experience is about or of. The singular content view faces well-known difficulties accommodating hallucinations; I maintain that there is also an analogue of Frege's puzzle that poses a significant problem for this view. In fact, I believe that this puzzle presents difficulties for the theory that are unique to perception in that strategies that have been developed to respond to Frege's puzzle in the case of belief cannot be employed successfully in the case of perception. Ultimately, I maintain that this perceptual analogue of Frege's puzzle provides a compelling reason to reject the singular content view of perceptual experience.
\end{abstract}

\section{Introduction}

According to an influential and widespread view, many beliefs (and other propositional attitudes) are constitutively dependent on the particular physical objects that they are about. For instance, many philosophers maintain that to believe that Hesperus is bright is to stand in the belief relation to a singular proposition that includes Venus itself as a constituent. Yet, despite its prevalence, such a view has been plagued by two especially persistent difficulties. The first is that some mental states concern objects that don't exist. For example, if the belief that Hesperus is bright involves a proposition containing Venus itself, then presumably the belief that Santa Claus is fat involves a proposition containing Santa Claus himself; but there is no such proposition because there is no such individual. The second-known as Frege's puzzle-is that there are cases where two given beliefs seem to have distinct contents despite the fact that they differ only with respect to, say, the names that the subject uses to think of some particular object. For example, if the content of the belief that Hesperus is bright is the proposition composed of Venus and the property of being bright, then the belief that Phosphorus is bright has the very same content; but this consequence is problematic for a number of familiar reasons. 
There is an analogous view of perceptual experience according to which perceptual experiences are constitutively dependent on the particular physical objects that they are about or of. More specifically, according to what I will call the singular content view the contents of perceptual experiences include singular propositions partly composed of the particular physical object(s) a given experience is about or of. One might expect the singular content view to be plagued by difficulties similar to those that plague the analogous view of belief. There is an obvious parallel between beliefs concerning objects that don't exist and hallucinations, and as one might expect, a good deal has been written concerning whether the singular content view can respond convincingly to the problem posed by hallucinations. ${ }^{1}$ But, surprisingly, the question of whether this view faces difficulties analogous to Frege's puzzle has received little or no attention. ${ }^{2}$

I maintain that there is an analogue of Frege's puzzle that poses a significant problem for the singular content view. In fact, I believe that this puzzle, unlike hallucinations, presents difficulties for the theory that are unique to perception. For example, one well-known strategy for accommodating beliefs concerning non-existent objects is to appeal to gappy propositions; and there is no obvious reason why a defender of the view that perceptual contents are singular propositions shouldn't adopt this very same strategy in order to accommodate hallucinations. ${ }^{3}$ Conversely, I argue that strategies that have been developed to respond to Frege's puzzle in the case of belief cannot be employed successfully in the case of perception (in this sense, Frege's puzzle is even more puzzling in the case of perceptual experience than in the case of belief). In fact, I maintain that none of the most natural responses to this puzzle provides a successful solution. Ultimately, I hope to show that an analogue of Frege's puzzle provides a compelling reason to reject the singular content view of perceptual experience. ${ }^{4}$

First, in $\S 1 \mathrm{I}$ describe the singular content view in greater detail. In $\S 2 \mathrm{I}$ describe a puzzle case where a particular object is misperceived to be two distinct objects and explain why the example constitutes a significant difficulty for the view at issue. Then, in $\S 3$ I consider what I take to be the

1 See, for example, Tye (2007), Pautz (2010), and Sainsbury and Tye (2012, 150-157).

2 Siegel (2013, 332-339) and Chalmers (2013, 359-364) discuss the possibility of perceptual Frege cases, but they focus on the perception of properties rather than the perception of objects.

3 For an account of the relevant belief contents, see Braun (1993). Philosophers who have characterized the contents of hallucinations as gappy propositions include Bach (2007), Tye (2007), Chalmers (2010), and Schellenberg (2010).

4 Defenders of naive realism-the view that to perceive is to stand in a primitive, non-representational relation of acquaintance to ordinary physical objects-also understand perceptual experiences to be object-dependent. Consequently, I think the puzzle also provides a compelling reason to reject naive realism, but in what follows I will restrict the argument to the singular content view. 
most plausible responses available to the singular content theorist and argue that none is ultimately acceptable.

\section{The Singular Content View}

An experience is a particular phenomenally conscious mental state or eventone that is like something for its subject. Perceptual experiences are those experiences characteristic of the different sense modalities that at least ostensibly involve the presentation of physical objects and their properties. According to the content view, to have a perceptual experience is to be the subject of a representational mental state or event. A representational mental state or event is one with a representational content; its content is the way the state or event represents the world as being. Standardly, the content of a perceptual experience is understood to be a proposition to which the subject stands in what we can call the perceptually-experiencing-relation. In other words, the content theorist claims that perceptual experience is a unique kind of propositional attitude: just as to believe that the book is on the table is to stand in the belief relation to the proposition that the book is on the table, to have a perceptual experience of the book on the table is to stand in the perceptually-experiencing-relation to the proposition that the book is on the table. ${ }^{5}$

Because the content theorist characterizes perceptual experience in terms of a relation to a proposition rather than to a physical object, she is not immediately committed to the view that perceptual experiences are constitutively dependent on the particular objects they are of. ${ }^{6}$ However, some defenders of the content view maintain that the contents of perceptual experiences are constitutively dependent on particular physical objects. According to the standard such view, a perceptual experience of a given physical object has as a content a singular proposition that includes that very object as a constituent. I will say that any theory that claims that perceptual contents include such singular propositions is committed to the singular content view. Conversely, I will say that any theory that claims that no perceptual contents include such singular propositions is committed to the general content view. Unlike the singular content theorist, the general content theorist is not necessarily committed to an object-dependent theory of perceptual experience.

5 Similar accounts of the content view are presented by Thau $(2002,74)$, Byrne (2009, 437-438), and Pautz (2009, 492; 2010, 257-259). Siegel (2010, chap. 2) presents a weaker version of the content view that she claims is consistent with naive realism; she calls the view described above the "Strong Content View." For an argument in favour of preferring the stronger characterization, see Pautz $(2009, \S 1)$. restricted to non-hallucinatory experiences. So, from now on, by "perceptual experience" I mean "non-hallucinatory perceptual experience" unless I specify otherwise. 
It should be noted that, as I've defined it, the singular content view comes in a number of different varieties. Perhaps the simplest variety understands the content of a given perceptual experience to be a Russellian proposition composed of the particular objects, properties, and relations that the subject perceives. A more complex variety maintains that perceptual experiences possess multiple contents, some of which are not singular propositions. For example, one might hold that when you perceive a particular blue book (Book) on a nearby table, your experience represents both the singular proposition composed of Book and blueness, and the general proposition that the book on the table is blue. Or, one might hold that in addition to the singular proposition composed of Book and blueness, your experience also represents a Fregean proposition composed of modes of presentation of Book and of blueness. $^{7}$ And, of course, there are many other possible varieties of similar complexity.

The general content view comes in a number of different varieties as well. A common variety understands the contents of perceptual experiences to be general rather than singular Russellian propositions (composed of the properties and relations, but not the particular physical objects, that the subject perceives). ${ }^{8}$ For instance, a defender of such a view will claim that the content of your perceptual experience of Book does not include Book itself, but is a general proposition such as that the book on the table is blue. Another variety understands perceptual contents to be Fregean propositions composed of modes of presentation of objects and properties. Yet another denies that perceptual contents are structured propositions, and claims instead that they are sets of possible worlds. ${ }^{9}$ And, of course, there are

7 The simple Russellian view is defended by Tye (2007) and Speaks (2009). A multiple content view that includes general propositions is defended by Byrne and Logue (2008) and Siegel (2010, chap. 6). And a multiple content view that includes Fregean propositions is suggested by Peacocke (1992, chap. 3) and defended by Chalmers (2010). Schellenberg (2010) defends a view similar to Chalmers's, except that modes of presentation and particular physical objects are combined in a single layer of content. Soteriou (2000) argues that perceptual contents contain object-dependent "demonstrative elements" rather than particular objects, so his view does not qualify as a version of the singular content view as I've defined it; however, his view is sufficiently similar to the simple Russellian view that the arguments that follow should still apply to it.

8 It should be noted that the singular propositions that are relevant for present purposes are singular with respect to the particular physical objects perceived by the subject. A defender of the general content view as I've defined it can allow that the propositions that constitute the contents of perceptual experiences are singular with respect to other particulars (e.g., times or spatial locations).

9 The view that perceptual contents are general Russellian propositions is defended, for instance, by Searle (1983), Davies (1992), Tye (1995), and Pautz (2009). Burge (1991) defends a view that appeals to indexical modes of presentation of objects; Chalmers (2004) develops a more comprehensive Fregean view of perceptual content. Sainsbury and Tye (2012, chap. 8) defend the view that perceptual contents are sets of possible worlds. 
many other possible varieties that combine different elements of these views or that appeal to multiple contents.

I mentioned above that there are certain well-known problems that arise for theories that characterize beliefs as constitutively dependent on the particular physical objects they are about; accordingly, it's natural to assume that analogous problems will arise for the singular content view. The view has difficulties accommodating hallucinations that clearly parallel the problems posed by beliefs concerning non-existent objects: singular content theorists must provide a distinct account of the nature of hallucinatory perceptual experiences since when you suffer a hallucination there is no appropriate physical object to be included in the proposition that constitutes the content of your experience. But, in addition, the singular content view ought to face a difficulty analogous to Frege's puzzle; I describe just such a difficulty in the next section.

\section{The Puzzle}

One standard way to present Frege's puzzle involves a subject who mistakes one particular individual for two distinct individuals. ${ }^{10}$ For example, Lois Lane, on the basis of some very good evidence, mistakenly believes that "Clark Kent" and "Superman" refer to two different people. Lois's Clark Kent-beliefs and her Superman-beliefs play very different roles in her mental life, and many conflict with one another; and these facts are difficult to explain if you assume that the relevant belief contents contain the particular individual that those beliefs concern. Consider, for instance, Lois's belief that Clark Kent is not Superman. If the particular individual who goes by both "Clark Kent" and "Superman" is a constituent of the content of her belief, then the content of this belief is the same contradictory proposition expressed by saying that Clark Kent is not Clark Kent. But while it is irrational for a person to believe such a contradictory proposition, Lois's belief that Clark Kent is not Superman is perfectly rational.

If, then, we are looking for an analogue of Frege's puzzle that poses difficulties for the singular content view, we ought to consider a subject who mistakes one particular object for two distinct objects. More specifically, we need a subject who doesn't simply form mistaken beliefs about the relevant object, but rather misperceives that object. To illustrate the fact that certain stimuli can be perceived to consist of either one or two objects at different times, it may help to consider the following ambiguous figures.

The shape in figure 1 can be seen as either one larger triangle or two smaller triangles arranged side by side; and the image in figure 2 can be seen as 


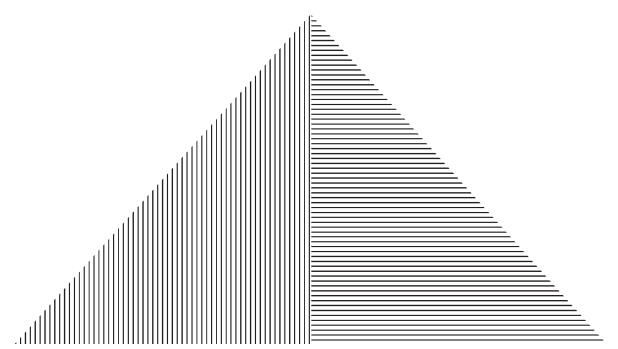

Figure 1.

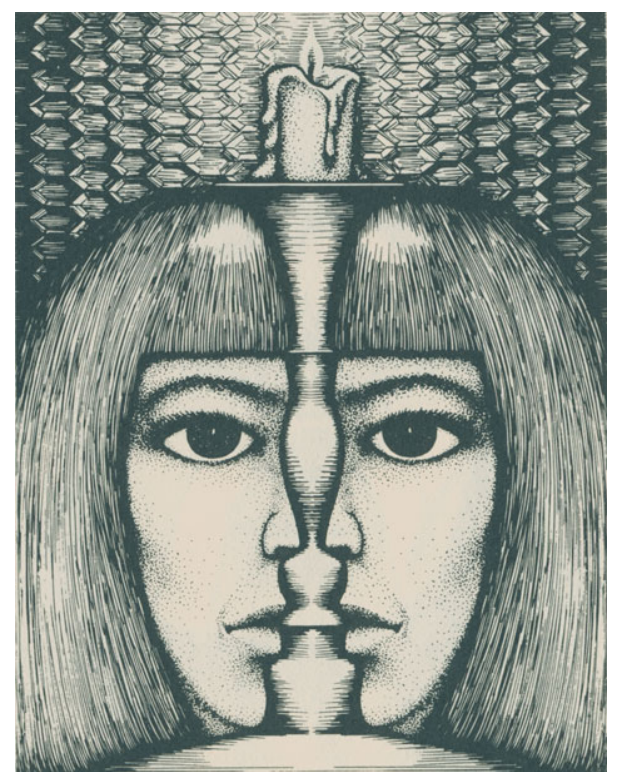

Figure 2.

either two faces in profile, or one rather wide face partially obscured by a candlestick. ${ }^{11}$ For present purposes, the crucial point is that when you see these images as consisting of two objects your visual experience itself is different from when you see them as consisting of a single object. That is, the difference in these cases does not seem to be simply a matter of the beliefs you form; rather, the phenomenal character or phenomenology of the relevant visual experiences (what it's like for you to have them) seems to be different.

Since we need a case where a subject misperceives a particular object to be two distinct objects, we can borrow an example from Perry (2001,

11 Figure 2: "Egyptian-eyezed Tete-a-tete" from the book MIND SIGHTS: Original Visual Illusions, Ambiguities, and Other Anomalies, With a Commentary on the Play of Mind in Perception and Art by Roger N. Shepard. Copyright (C) 1990 by Roger N. Shepard. Reprinted by permission of Henry Holt and Company, LLC. All rights reserved. 
63-64). ${ }^{12}$ Suppose there is a dog with an unusually long torso, named "Stretch," curled around a small pillar or post, and that from your vantage point a portion of Stretch's midsection is obscured by this pillar. Suppose further that Stretch is standing in precisely the position required to create an effective ambiguous stimulus. ${ }^{13}$ For instance, we might imagine that there is a tension between different Gestalt grouping principles: perhaps, on the one hand, due to the way Stretch's torso is contorted, the visible parts of his body do not achieve 'good continuation' (which would tend to cause you to perceive the scene as consisting of two dogs); but, on the other hand, these visible parts are the same colour and size (which would tend to cause you to perceive the scene as consisting of a single dog). ${ }^{14}$ The result is that from your vantage point the scene in question might be perceived as a single dog positioned such that part of its midsection is occluded by the pillar, or as two stubbier dogs situated such that the head and front legs of the dog to your left and the tail and back legs of the dog to your right are occluded by the pillar. Now, imagine that upon your initial glimpse of this scene you have a visual experience, $E$, in virtue of which you misperceive that there are two dogs in front of you. More specifically, on the basis of your visual experience you would say that there is a particular dog whose back half occupies a particular region of space to the left of the pillar, $\mathrm{L}_{1}$, and a numerically distinct dog whose front half occupies a particular region of space to the right of the pillar, $\mathrm{L}_{2}{ }^{15}$

Presumably, in order to see a particular dog it's sufficient to have a clear visual experience of one side of half of that dog. As such, the singular content theorist will want to grant that whatever conditions must be satisfied in order for a subject to visually represent a particular physical object are satisfied by your perceptual contact with each half of Stretch in the present case. So, if perceptual contents are partly composed of the objects and properties the subject perceives, then E's content is partly composed of Stretch, the property of being such that one's back half occupies $\mathrm{L}_{1}$, and the property of

Bach $(1987,22)$ and Braun $(2007, \S 4.2)$ describe similar examples where a particular object is visually perceived to be two distinct objects. Austin (1990) discusses a case in which a subject has two distinct but simultaneous visual experiences of a particular object and is uncertain whether these experiences are of the same object. Austin, Bach, Braun, and Perry are interested in the content of utterances and beliefs that result from these experiences rather than the content of the experiences themselves.

The photograph on the cover of Perry (2001) should provide a rough sense of the stimulus being described. However, I don't find the photograph terribly effective, so please try to imagine a scene that you would more readily perceive as containing a single dog. For an overview of the relevant Gestalt principles, see Palmer (1999, chap. 6).

While perceptual experiences are typically enormously complex, I will be focusing exclusively on those aspects of the perceptual experiences at issue that are directly relevant to the puzzle. That is, I will be focusing on Stretch and his location properties, while ignoring the pillar, properties such as colour and shape, and so on. 
being such that one's front half occupies $\mathrm{L}_{2}$. But the claim that E's content is partly composed of Stretch and these specific properties is problematic because it appears to be at odds with the fact that in the present case you misperceive the scene as including two distinct dogs.

We can highlight the problem that this example poses for the singular content view by contrasting $E$ with a veridical perceptual experience of the same scene. Suppose that some time later Stretch occupies precisely the same position relative to the pillar, and that you observe the scene from the very same vantage point and under the same viewing conditions. But, imagine that this time when you view this ambiguous scene you have a visual experience, $E^{*}$, in virtue of which you accurately perceive that there is a single dog in front of you. More specifically, on the basis of $E^{*}$ you would say that there is a particular dog whose back half occupies $\mathrm{L}_{1}$ and whose front half occupies $\mathrm{L}_{2}$.

There are at least three important differences between $E$ and $E^{*}$ that the singular content view would seem to be unable to explain. First, $E$ and $E^{*}$ differ with respect to their phenomenal character. In order to deny that there is a phenomenal difference between these experiences presumably one would have to maintain that only the representation of the most basic properties such as colour and location contributes to perceptual phenomenology. However, a defender of such a view would be forced to deny that gestalt phenomena such as emergence and grouping make a phenomenal difference to visual experiences, and to insist that no perceptual phenomenal change occurs when we view many standard ambiguous figures (such as the 'Boring figure' that can be seen either as a young or an old woman). In any case, it should be apparent if you consider the divergent visual experiences you have of the images in figures 1 and 2 that what it's like for you to perceive a particular stimulus to consist of two objects is different from what it's like for you to perceive that stimulus to consist of a single object. Accordingly, it seems plausible that simply by reflecting on what it's like for you to undergo $E$ and $E^{*}$ you would be able to distinguish these experiences from one another.

Now, one might wonder why the singular content theorist should be required to explain the fact that there is a phenomenal difference between $E$ and $E^{*} .{ }^{16}$ After all, the singular content theorist is not required to endorse representationalism - the thesis that phenomenal character supervenes on representational content. However, even if representationalism is false, the kind of phenomenal difference at issue is most naturally explained in terms of a difference of perceptual content. It may be that some differences of perceptual phenomenology do not result from differences of perceptual content. For instance, perhaps we can have a visual experience in which the

16 Thanks to an anonymous referee for raising this issue. 
'visual static' or 'phenomenal noise' that permeates the visual field changes without any accompanying change of representational content. ${ }^{17}$ But a phenomenal change of this sort can occur without any accompanying change of representational content precisely because visual static is disconnected from how the mind-independent objects we perceive seem to us to be. Conversely, in the present case, the reason it is plausible to assume that there is a phenomenal difference between $E$ and $E^{*}$ is because when you undergo $E$ you seem to perceive two dogs, whereas when you under $E^{*}$ you seem to perceive a single dog. Similarly, when you switch from seeing the image in figure 2 as a single face to seeing it as two distinct faces, presumably the phenomenal character of your experience changes in virtue of the fact that the way the image seems to you has changed. That is, regardless of whether representationalism is true, a phenomenal change of this sort is most naturally understood as resulting from a change of how your visual experience represents the image to be.

The second important difference between $E$ and $E^{*}$ that the singular content view would seem to be unable to explain is that the mental and physical responses that $E$ would cause are different from those that $E^{*}$ would cause. For instance, if we assume that your mood always improves just slightly whenever you perceive a single dog, and that you are always made exactly twice as happy whenever you perceive two dogs together, then $E^{*}$ will cause your mood to improve just slightly whereas $E$ will make you exactly twice as happy. Or, suppose that you have a long-standing policy of giving every dog you encounter one (and only one) biscuit, and that you always carry biscuits in your pocket for this purpose. Then, $E$ will cause you to retrieve two biscuits from your pocket, whereas $E^{*}$ will cause you to retrieve only one biscuit from your pocket.

Third, the beliefs and actions that $E$ provides reasons for are different from the beliefs and actions that $E^{*}$ provides reasons for. For instance, when you undergo $E$ you have good reasons to believe that there are two dogs in front of you, but when you undergo $E^{*}$ you do not have good reasons to believe that there are two dogs in front of you. And given your biscuit distribution policy, in the case where you undergo $E$ it is perfectly rational for you to retrieve two biscuits from your pocket. If in these circumstances you were to retrieve only one biscuit from your pocket, due perhaps to faulty reasoning of some kind, you would be behaving irrationally. Conversely, in the case where you undergo $E^{*}$ you have good reasons to retrieve one biscuit from your pocket and do not have good reasons to retrieve two biscuits.

The difficulty, then, is that it's not clear that the singular content theorist will be able to identify a difference between the case in which you undergo 
$E$ and the case in which you undergo $E^{*}$ that adequately explains these three important differences. According to the singular content view, the content of $E^{*}$ will be partly composed of Stretch, being such that one's back half occupies $\mathrm{L}_{1}$, and being such that one's front half occupies $\mathrm{L}_{2}$; but, of course, these things are all constituents of the content of $E$ as well. Moreover, while the singular content theorist might want to claim that $E$, unlike $E^{*}$, is an illusory representation of the presence of two dogs, it's not clear that she can do so without characterizing $E$ as representing the contradictory proposition that Stretch is not identical to Stretch. But, the claim that the content of $E$ is a contradictory proposition is no more plausible than the claim that Lois Lane believes that Clark Kent is not Clark Kent; in fact, the claim that a perceptual experience represents something impossible is much less plausible than the corresponding claim regarding Lois's belief (more on this point below). So, the singular content theorist would appear to be unable to identify a difference between the content of $E$ and $E^{*}$ that would explain why $E$ should differ from $E^{*}$ in the ways just described.

By way of contrast, the general content view has no apparent difficulty explaining the relevant differences between $E$ and $E^{*}$. For instance, someone who maintains that the contents of perceptual experiences are general Russellian propositions can claim that the content of $E$ is something like the following: that there is a dog whose back half occupies $L_{1}$, and there is a dog whose front half occupies $L_{2}$, and the dog that occupies $L_{1}$ is not identical to the dog that occupies $L_{2}$. And further, a defender of this view can claim that the content of $E^{*}$ is something like: that there is a dog whose back half occupies $L_{1}$ and whose front half occupies $L_{2}$. Such a view straightforwardly captures the fact that $E$ misrepresents the presence of two distinct dogs, and does so without attributing contradictory content to this experience; and the fact that $E$ is a misrepresentation of the presence of two dogs while $E^{*}$ is an accurate representation of a single dog satisfactorily explains why $E$ and $E^{*}$ differ phenomenally, cause different responses, and provide reasons for different beliefs and actions.

Thus, the example poses a significant problem for the singular content view. We have good reasons to think that there are significant differences between $E$ and $E^{*}$; and we have prima facie reasons for maintaining that if the singular content view were correct then these specific differences would not obtain; so, we have prima facie reasons for concluding that the singular content view is false. We need to consider a number of additional proposals in order to determine whether this theory ultimately has the resources to provide a solution to the puzzle; but if none of the most plausible potential solutions are successful then we ought to reject the singular content view. 


\section{Responses}

The singular content theorist might attempt to explain the relevant differences between $E$ and $E^{*}$ in a number of different ways. I will divide the potential explanations into two groups: those that appeal only to the representation of objects, properties and relations, and those that appeal to ways of representing these aspects of content. I will call views that offer the former type of explanation pure singular views, and those that offer the latter type of explanation impure singular views. I can't hope to exhaust all the possible responses to the puzzle, but I will survey what I take to be the most natural and most plausible potential responses a defender of the singular content view might provide.

\subsection{Pure Singular Views}

There are three ways a defender of a pure singular view might attempt to explain the relevant differences between $E$ and $E^{*}$ that ought to be considered. First, one might claim that there is no difference with respect to the properties or relations represented by $E$ and $E^{*}$, but that the contents of these experiences are propositions with different structures. Second, one might claim that $E$ and $E^{*}$ represent different properties or relations to obtain. And third, one might claim that the apparent differences between $E$ and $E^{*}$ are due to the fact that, under the relevant circumstances, each gives rise to different judgements. I will consider each of these proposed solutions to the puzzle in turn.

Perhaps the simplest response would be to grant that $E$ and $E^{*}$ do not differ with respect to the objects, properties, or relations that they represent, and claim instead that they differ with respect to the structure of their contents. The singular content view understands (at least some of) the contents of perceptual experiences to be propositions that are composed out of ordinary physical objects, and various other elements, arranged in a certain structure. So, such a theorist might claim that even though the elements that make up the contents of $E$ and $E^{*}$ are the same, the structure of the relevant propositions is different. A natural development of this suggestion is the claim that the content of $E$ is a proposition consisting of two components, represented by the following ordered pairs:

$<$ Stretch, being such that one's back half occupies $\mathrm{L}_{1}>$

and

$<$ Stretch, being such that one's front half occupies $\mathrm{L}_{2}>$.

Whereas the content of $E^{*}$ is a proposition represented by the following ordered pair: 
$<$ Stretch, being such that one's back half occupies $\mathrm{L}_{1}$ and one's front half occupies $\mathrm{L}_{2}>$.

However, this response is insufficient for at least two reasons. First, it's not plausible that perceptual contents are individuated as finely as this proposal requires. And second, even if we were to grant that the contents $E$ and $E^{*}$ differ along these lines, this proposal could not hope to explain each of the previously outlined differences between these experiences. In particular, the proposed difference concerning the structure of these contents makes no difference to the beliefs and actions each experience provides reasons for. For instance, if $E$ represents that the back half of Stretch's body occupies $\mathrm{L}_{1}$ and that the front half of Stretch's body occupies $\mathrm{L}_{2}$, then this experience does not provide you with a reason to believe that there are two dogs in front of you, or to retrieve two biscuits from your pocket.

So, given that a mere structural difference between the relevant contents would not explain the differences between $E$ and $E^{*}$, perhaps a more promising response to the puzzle would be to claim that the contents of these experiences are composed of different elements. However, when you undergo both $E$ and $E^{*}$ you accurately perceive the very same dog-parts to occupy the very same locations - if there is a difference of perceptual content here, it concerns only whether the relevant dog-parts belong to a single dog or two distinct dogs. Accordingly, someone who responds to the puzzle by claiming that these experiences represent different properties or relations must claim that $E$, unlike $E^{*}$, represents that the dog occupying $\mathrm{L}_{1}$ is not identical to the dog occupying $\mathrm{L}_{2}$. But, the singular content theorist maintains that, in virtue of being the particular object that occupies both relevant locations, Stretch himself is the only particular object that is a constituent of the content of $E$; and so, this proposal entails that the content of $E$ includes the contradictory proposition that Stretch is not identical to Stretch.

(This difficulty arises regardless of whether one adopts the view that the content of $E$ is a single singular proposition, or claims instead that $E$ possesses multiple contents. For instance, a defender of the latter view might claim that $E$ and $E^{*}$ both have as content a singular proposition composed of Stretch, being such that one's back half occupies $\mathrm{L}_{1}$, and being such that one's front half occupies $\mathrm{L}_{2}$; and that $E$, unlike $E^{*}$, has an additional content, such as the general proposition that the object that occupies $L_{1}$ is not identical to the object that occupies $L_{2}$. But, so long as the different contents of the experience are jointly inconsistent the 
present proposal characterizes $E$ as representing an impossible state of affairs. $)^{18}$

I said above that the claim that $E$ represents something impossible seems implausible; in fact, there are conclusive reasons for rejecting this proposal. First, there are reasons to think that no particular visual experience in a subject with a normally functioning visual system ever actually represents an impossible state of affairs. In this respect, perceptual experiences are unlike beliefs; and accordingly, there is an important difference here between Frege's puzzle for belief and Frege's puzzle for perception. We know independently of any Frege cases that people sometimes believe propositions that are necessarily false. For instance, someone who isn't particularly good at math might believe that the square root of 80 is 9 . Conversely, it's not at all clear that there are any independent examples of visual experiences that represent something impossible. Those who maintain that some visual experiences possess contradictory content typically rely on two examples: the motion aftereffect or 'waterfall illusion,' and visual experiences of 'impossible figures' such as the Penrose triangle. ${ }^{19}$ However, as Bayne (2007, 203) notes, in both cases one may plausibly claim that the incompatible properties are not represented to belong to the relevant object at the same time. And, in addition, those circumstances that are most conducive to producing experiences representing impossible states of affairs-for instance, cases involving binocular rivalry or viewing an ambiguous figure-instead produce fluctuations between experiences representing coherent scenes. ${ }^{20}$

A second problem with the proposal that $E$ represents an impossible state of affairs is that, even granting for the moment that some perceptual experiences possess such contents, we still have good reasons to think that $E$ is not an experience of this sort. The only plausible examples of visual experiences with the relevant contents are experiences of 'impossible figures' and the waterfall illusion. However, when you undergo these experiences you are immediately aware that there is something strange about them-the conflict between the different elements of the experience is something you

18 Another possibility would be to claim that the content of $E^{*}$ includes a singular proposition containing Stretch as a constituent, but that $E$ does not (for instance, one might claim that the contents of $E$ include only general propositions). While such a proposal would avoid attributing contradictory content it is too clearly ad hoc to be given serious consideration. In addition, it's not clear what reasons a defender of such a view could give for maintaining that $E$ does not possess a singular content that would not tend to undermine the singular content view more generally.

See, for example, Crane (1988), Peacocke (1992, 73-74), Tye (2000, 75), Pautz (2010, 280-281), and Matey (2012).

Tononi and Edelman (1998) and Bayne (2007) both appeal to binocular rivalry and ambiguous figures in support of the claim that perceptual experiences never actually represent impossible states of affairs. See Blake (2001) for a detailed account of the phenomenon of binocular rivalry. 
sense automatically, without any active introspection on your part. In this respect, perceptual experiences are unlike beliefs: one can believe something that can't be true, for instance by having a false mathematical belief, without being aware that there is anything unusual about one's belief. Consequently, we should assume that if $E$ really did possess contradictory content, you would be immediately aware that there was something strange about the experience; but, to the contrary, $E$ is a perfectly ordinary experience as of two dogs partially obscured by a pillar.

A third problem with the proposal at issue is that, even granting for the moment that $E$ represents an impossible state of affairs, this fact would not explain the difference between the mental and physical responses that $E$ and $E^{*}$ would cause. If $E$ represents that Stretch is not identical to Stretch, then it's not clear why this experience would produce anything other than a feeling of confusion. But in any case, it's certainly false that an experience with this content would be more likely to cause you to believe that there are two dogs in front of you than that there is one dog in front of you, and be more likely to cause you to retrieve two biscuits from your pocket than to retrieve one biscuit from your pocket. Consequently, even if this proposal were not unacceptable for independent reasons, it would not constitute a satisfactory solution to the puzzle.

One might try to avoid attributing contradictory content to $E$ by claiming that parts of objects - specifically their visible surfaces - are constituents of perceptual contents. That is, one might claim that there is a surface to the left of the pillar, $S_{1}$, and a numerically distinct surface to the right of the pillar, $\mathrm{S}_{2}$, and that while $E$ represents that $\mathrm{S}_{1}$ and $\mathrm{S}_{2}$ belong to two distinct objects (which is false but not contradictory), $E^{*}$ represents that $S_{1}$ and $S_{2}$ belong to a single object. The difficulty with such a proposal, however, is that visual experiences do not simply represent the locations of discrete, unbroken surfaces, but also the objects to which those surfaces belong. ${ }^{21}$ Consequently, a defender of the present proposal must address the question of whether the object that the relevant parts are represented as belonging to is itself a constituent of the content; answering yes would raise the problem of contradictory content again, and answering no would tend to undermine the singular content view more generally. ${ }^{22}$

Finally, a defender of a pure singular view might attempt to avoid the difficulties associated with the previous responses to the puzzle by maintaining that the purported differences between $E$ and $E^{*}$ are explained by the

21 There is a good deal of empirical evidence that visual experiences represent objects and not merely discrete, unbroken surfaces. For reviews of some of that evidence, see Scholl (2001) and O'Callaghan (2008). cated examples where the same surface of an object is seen twice (e.g., involving mirrors, or double vision). 
fact that they precipitate different judgements. For instance, one might claim that $E$ and $E^{*}$ have the same content: the proposition composed of Stretch, being such that one's back half occupies $\mathrm{L}_{1}$, and being such that one's front half occupies $\mathrm{L}_{2}$. Or, one might claim that the content of $E$, but not the content of $E^{*}$, is somehow neutral concerning whether the dog whose back half occupies $\mathrm{L}_{1}$ is numerically identical to the dog whose front half occupies $\mathrm{L}_{2}$. But, whichever characterization of the content of these experiences is correct, the important point is that when you undergo $E$ you form a judgement the content of which is the general proposition that the object that occupies $L_{1}$ is not identical to the object that occupies $L_{2}$. In other words, according to the present proposal, the differences between the case in which you undergo $E$ and the case in which you undergo $E^{*}$ are explained by the fact that you make a faulty judgement in response to $E$ that you avoid making in response to $E^{*}$.

Essentially, this proposal maintains that the mistake involved in the case in which you undergo $E$ is due to a post-perceptual judgement, rather than to your perceptual experience itself. The principal difficulty, then, is that there is simply no reason to assume that the mistake involved in the case in which you undergo $E$ must occur at the level of post-perceptual cognitive states. Determining which elements of a visible scene belong to the same objects and which belong to distinct objects is something that occurs quickly and automatically at the level of perceptual representation. ${ }^{23}$ In addition, the representation of those parts of objects that are occluded by other objects (that is, 'amodal completion') also occurs quickly and automatically at the level of perceptual representation, prior to the judgements that a subject forms in response to her perceptual experiences. ${ }^{24}$ So, if we assume that perceptual experiences are representational mental states or events, we should assume that they represent which visible surfaces belong to which objects, and whether those objects continue behind occluders. Accordingly, we should assume that perceptual experiences can misrepresent that two particular surfaces belong to two distinct, partly occluded objects, just as easily as they can misrepresent an object's size or shape. Of course, you can form mistaken judgements regarding the number of objects in front of you in response to your perceptual experiences; the present point is just that sometimes such misrepresentations arise at the level of perceptual experience itself. And if that's so, then we can simply stipulate that in the case where you undergo $E$, your visual experience misrepresents that there are two distinct objects partly occluded by the pillar in front of you, and that when you undergo $E^{*}$ your visual experience accurately represents that there is a single object partly 
occluded by the pillar in front of you. Consequently, appealing to the nature of the judgements you form in response to these experiences won't enable the singular content theorist capture how $E$ and $E^{*}$ differ from one another.

\subsection{Impure Singular Views}

Frege's puzzle is often taken to demonstrate that an adequate theory of belief needs to take into account the way that the subject thinks about the object a belief concerns. As we've seen, pure singular views attempt to solve the perceptual analogue of Frege's puzzle while appealing only to the representation of objects, properties and relations; so, the lesson that a defender of the singular content view might draw from the failure of these proposed solutions is that an adequate theory of perceptual content must take into account the way that perceived objects are represented in perceptual experience.

We can distinguish two different approaches to characterizing these ways that objects are represented. First, philosophers who maintain that some of the contents of beliefs are singular propositions often introduce an element that serves as an intermediary between the subject and the proposition; that is, they claim that underlying the belief relation is a three-place relation between a subject, a proposition, and a way of taking or representing that proposition. Following Salmon (1986, chap. 8), I will call these mediating entities guises. Typically, guises for singular propositions are understood to have parts that are guises for particular objects. For instance, Lois can think thoughts about Clark/Superman by tokening the name "Superman" in inner speech or by tokening the name "Clark Kent"- these names are two distinct ways of representing the same particular individual.

Second, on the standard Fregean view, belief contents contain modes of presentation of objects. Typically, a mode of presentation is understood to consist of some condition that a given object satisfies - a particular object is the object the belief concerns in virtue of satisfying this condition. (Modes of presentation are therefore, like guises, intermediaries between the subject and the object the belief concerns; but, as I will use this terminology, modes of presentation are always constituents of the contents of mental states while guises never are.) The traditional Fregean view is that modes of presentation are constituents of belief contents rather than particular physical objects; but one can also maintain that particular objects and the modes of presentation of those objects are both constituents of belief contents.

For present purposes, the important question is whether a defender of the singular content view can explain the relevant differences between $E$ and $E^{*}$ by appealing to different ways of representing the scene in question. I will first consider whether appealing to different guises will allow the singular content theorist to solve the puzzle, and then consider whether modes of presentation provide a more plausible alternative. 


\subsubsection{Guises}

Appealing to guises would allow the singular content theorist to approach the differences between $E$ and $E^{*}$ in two different ways. One might claim that $E$ unlike $E^{*}$ represents the contradictory proposition that Stretch is not identical to Stretch, but that the problems concerning contradictory perceptual content identified above are obviated by the fact that Stretch is represented to occupy $\mathrm{L}_{1}$ and $\mathrm{L}_{2}$ via two distinct guises. Or, one might claim that $E$ and $E^{*}$ have the same content and that the differences between them are due to the fact that $E$ involves Stretch being represented to occupy $\mathrm{L}_{1}$ and $\mathrm{L}_{2}$ via two distinct guises, while $E^{*}$ involves Stretch being represented to occupy $\mathrm{L}_{1}$ and $\mathrm{L}_{2}$ via a single guise. Anyone attempting to solve the puzzle by appealing to guises, then, claims that when you undergo $E$ Stretch is represented to occupy $\mathrm{L}_{1}$ via one guise and represented to occupy $\mathrm{L}_{2}$ via a distinct guise.

This proposal fails because there are no representational entities that are plausible candidates for the guises in question. In the case of belief, guises are characterized in a number of different ways; but the only approach that could plausibly be extended to perceptual experiences is to appeal to the relevant representational vehicles, presumably brain states of some kind or other. $^{25}$ The difficulty, then, is that the representational vehicles of perceptual contents cannot play the role that the singular content theorist needs them to play in order to handle the puzzle case.

It's plausible that the representational vehicles of belief contents have a sentence-like structure, such that specific brain states representing specific objects, properties, and relations represent specific propositions in virtue of being organized or connected in the right way. Accordingly, one can maintain, as Braun (1998, 574-576) does, that the guise for a given belief content is a "mental sentence" representing the relevant proposition. The advantage of such a view in the present context is that linguistic entities are well suited to provide distinct ways of representing one and the same thing. For instance, we often use two different names to refer to a particular individual; and as a result, there is a clear sense in which "Louis Armstrong plays cornet" and "Satchmo plays cornet" constitute two different ways of expressing the same proposition. Similarly, I refer to myself with "I" and you might refer to me with "you"; and as such, the claim that when I say "I'm hungry" and you say "you're hungry" we express the very same proposition in two different ways is quite intuitive. ceptual experiences of the object the belief concerns (Salmon 1986, 109) or to depend on such experiences (Crimmins and Perry 1989, 695-696); and, of course, we can't explain how perceptual experiences represent their contents by appealing to other perceptual experiences. For accounts of guises as representational vehicles, see, for example, Soames $(1995,522)$ and Braun $(1998,573-574)$. 
Linguistic expressions like names and indexicals thus provide different ways of representing the same thing precisely because, in and of themselves, they are not devices for distinguishing between individuals; we often use different names to distinguish between individuals, but this only works so long as the names in question actually represent distinct individuals. However, the representational vehicles for the contents of perceptual experiences have a map-like rather than a sentence-like structure; and whatever symbolic device is used within a map to represent particular entities of a certain sort is also a device for distinguishing between such entities. For instance, suppose that I'm creating a map of North America and that I'm using expanses of colour to identify the region that each country occupies. Suppose further that I've mistaken Canada for two distinct countries, one extending from the U.S. border to the 60th parallel, and the other occupying the land north of the 60th parallel. As a result, I fill in the region of my map representing the land between the U.S. border and the 60th parallel with red, and I fill in the region of my map representing the land north of the 60th parallel with yellow. The resulting red and yellow regions of my map are not two different ways of representing one and the same country. My map does not represent that Canada occupies two distinct regions of North America; rather, it represents that two distinct countries occupy the region that Canada actually occupies. (Conversely, using two different names for Canada, I would have no trouble at all producing sentences representing Canada to occupy two distinct regions of North America.)

Assuming, then, that the representational vehicles for the contents of perceptual experiences involve neural maps, it follows that, contrary to what the present proposal requires, Stretch is not represented via two distinct guises within $E$. The scientific consensus is that visual representations involve activity across distinct arrays of neurons sensitive to different features (such as shape, or size); a conscious visual representation of an object arises thanks to whatever mechanism combines the representations of different features across different neural maps into a unified percept. ${ }^{26}$ While the nature of the mechanism that unites the different representational elements is still a matter of dispute, we can assume that whatever device the visual system uses to represent objects will also be a device for distinguishing between objects. Consequently, when you undergo $E$, the relevant neural representations do not represent Stretch to occupy two distinct locations any more than my map represents Canada to occupy two distinct regions of North America.

For the sake of illustration, assume that the 'binding by synchrony' theory is correct. According to this theory groups of neurons across different maps form a unified representation of an object in virtue of firing synchronously 
with one another and asynchronously with other groups of neurons. ${ }^{27}$ If this view is accurate, when you undergo $E$ Stretch is only represented via two distinct guises so long as there are two distinct groups of neurons in your brain: a first group responding to Stretch's back half, the members of which are firing synchronously with one another but asynchronously with neurons from the other group; and a second group responding to Stretch's front half, the members of which are firing synchronously with one another but asynchronously with neurons from the first group. The difficulty for the present proposal, then, is that not only is the synchrony within a group a way of representing the presence of a particular object, but the asynchrony between groups is a way of representing that two objects are distinct (just as, on my map, an expanse of colour represents a particular country and a difference between colours represents that two countries are distinct). Consequently, the singular content theorist cannot claim that when you undergo $E$, Stretch is represented to occupy distinct locations via distinct guises - this claim is incompatible with the nature of the relevant representational vehicles.

\subsubsection{Modes of Presentation}

The other approach to explaining the important differences between $E$ and $E^{*}$ in terms of different ways the relevant scene is represented involves appealing to modes of presentation. A singular content theorist who invokes modes of presentation maintains that a given perceptual experience possesses both a singular content (a proposition partly composed of the object the experience concerns) and a Fregean content (a proposition partly composed of modes of presentation of the object the experience concerns, rather than the object itself). ${ }^{28}$ So, just as the defender of the singular content view who invokes guises maintains that when you undergo $E$ Stretch is represented via two distinct guises, a defender of the view who invokes modes of presentation claims that $E$ 's Fregean content includes two distinct modes of presentation of Stretch.

The difficulty the puzzle poses for the theorist who invokes guises is that there does not seem to be any plausible characterization of the relevant guises

27 The 'binding by synchrony' theory remains controversial: for a review of the relevant evidence, see Uhlhaas et al. (2009). I focus on this theory because it provides a reasonably simple account of what distinguishes the different visual experiences one has of ambiguous stimuli of the sort at issue. For some details concerning what the theory predicts about cases where different elements are seen sometimes to compose a single object and sometimes as consisting of distinct objects, see Engel et al. (2001, 707). Knyazeva et al. (2011) provides evidence that synchrony plays a role in these cases. are combined in a single component of content, but the difference between these views has no bearing on the arguments that follow. 
such that one may claim that when you undergo $E$ Stretch is represented to occupy distinct locations via distinct guises; the singular content theorist who invokes modes of presentation faces a similar difficulty. To illustrate the difficulty with this approach we can focus on Chalmers's $(2004 ; 2010)$ account of the Fregean contents of perceptual experiences. ${ }^{29}$ According to Chalmers, each distinct aspect of the phenomenology of a visual experience is associated with a specific mode of presentation - a condition that an object or property must satisfy in order to be picked out by the experience. We determine what the condition associated with a given phenomenal property is by considering the ways the world would have to be in order for an experience instantiating that property to be veridical. For instance, Chalmers (2004, 172-173; 2010, 374) claims that a given phenomenally red experience would be veridical in a number of different possible worlds where that experience is caused by different properties, but the property causing the experience in a given possible world must be the property that normally causes phenomenally red experiences in the perceiver in that world; accordingly, the Fregean content of a phenomenally red experience is a condition like being the property that normally causes phenomenally red experiences in the perceiver.

According to Chalmers, the mode of presentation associated with the "objectual" aspect of a given experience is a condition like being "the object that is causing this experience in the appropriate way" (2004, 173). But when a visual experience represents multiple objects, different aspects of the experience pick out different objects. For present purposes, we can call each aspect of an experience that involves the presentation of an apparent object a sensation. So, the present view is that in order for an object to be picked out by a particular sensation it must be the object that is causing that specific sensation in the appropriate way. In other words, the Fregean content associated with each distinct sensation is a condition like being the object that is causing this sensation in the appropriate way.

Accordingly, this view entails that $E$ involves two distinct modes of presentation of Stretch only so long as Stretch's front half and his back half cause this experience to instantiate distinct sensations. But, the claim that $E$ instantiates two distinct sensations is only plausible so long as we think of distinct sensations as presenting objects to be distinct. When you undergo $E^{*}$ each half of Stretch is responsible for a certain aspect of the phenomenology of your experience, and as a result, there seems to you to be an object occupying $\mathrm{L}_{1}$ and there seems to you to be an object occupying $\mathrm{L}_{2}$; nonetheless,

29 I focus on Chalmers's view because his account of perceptual modes of presentation of objects seems the most natural in the context of the present puzzle. For instance, Schellenberg's $(2010,35)$ view that the relevant modes of presentation place a condition on the kind of object that an experience concerns does not suggest any obvious response to the puzzle. 
because there seems to you to be a single object occupying both $\mathrm{L}_{1}$ and $\mathrm{L}_{2}$, $E^{*}$ instantiates a single sensation (and consequently $E^{*}$ 's Fregean content includes a single mode of presentation of this object). Conversely, when you undergo $E$, while there seems to you to be an object occupying $\mathrm{L}_{1}$ and an object occupying $\mathrm{L}_{2}$ there are two sensations (and two modes of presentation) because the objects occupying $\mathrm{L}_{1}$ and $\mathrm{L}_{2}$ are presented as distinct objects.

Consequently, Chalmers's account of the Fregean content of sensations needs to be amended. Again, we determine the condition associated with the relevant sensations by considering the ways the world would have to be in order for an experience instantiating such sensations to be veridical. But the present proposal requires that distinct sensations present objects to be distinct; so, any experience instantiating the two sensations that Stretch causes $E$ to instantiate is only veridical so long as a particular object is causing one of these sensations and a distinct object is causing the other sensation. Thus, the condition on extension associated with each sensation is not being the object that is causing this sensation in the appropriate way, but being the object that is causing this sensation in the appropriate way and that is not causing any distinct sensation instantiated by the same experience in the appropriate way.

But, of course, when you undergo $E$ Stretch is causing both of the relevant sensations, and so Stretch does not satisfy the condition associated with either. And since a particular physical object is a constituent of the singular content of an experience only so long as it is picked out by a mode of presentation included in the Fregean content of that experience, the present proposal entails that Stretch is not a constituent of the content of $E$ (in other words, E's Fregean content does not include two distinct modes of presentation of Stretch). In fact, since no object satisfies the condition associated with either of these two sensations, this proposal entails that $E$ has the very same content as a hallucination of two dogs. Presumably, most defenders of the singular content view would not be willing to adopt the view that $E$ is not a representation of Stretch. But, perhaps more importantly, the singular content theorist who invokes modes of presentation does not eliminate the difficulties posed by the puzzle so much as substitute a distinct set of difficulties - specifically, the difficulties the singular content view has accounting for the contents of hallucinations (an issue that is beyond the scope of the present argument).

\section{Conclusion}

We ought to conclude, then, that the singular content theorist cannot provide a satisfactory solution to the puzzle. Because this theory characterizes perceptual experiences to be constitutively dependent on the physical objects they are of, it doesn't seem to be able to account for illusions where a particular object is misperceived to be two distinct objects. And 
while there are plausible strategies for a defender of the related view of belief to respond to Frege's puzzle, we have now seen that the most natural strategies for responding to the perceptual analogue of Frege's puzzle are not ultimately successful. That is, Frege's puzzle appears to present an even greater challenge to object-dependent theories of perceptual experience than it does to analogous views of belief. Put briefly: in the case at issue we have good reasons to think that there are significant differences between $E$ and $E^{*}$; and we have now seen that there are good reasons for maintaining that if the singular content view were correct, these specific differences would not obtain. Consequently, we have good reasons for concluding that the singular content view is false.

The general content view does not face the same difficulty accounting for illusions of the sort at issue. As I mentioned above, the general content view comes in a number of different varieties, and I assume that almost any version of the view will be able to provide an equally satisfactory account of the differences between $E$ and $E^{*}$. Consequently, one would have to appeal to independent considerations in order to determine which specific variety of the general content view is best. However, the foregoing argument implies that we ought to reject the singular content view and endorse some variety of the general content view. ${ }^{30}$

\section{References}

Austin, David. 1990. What's the Meaning of 'This'? Ithaca, NY: Cornell University Press.

Bach, Kent. 1987. Thought and Reference. Oxford: Oxford University Press.

2007. "Searle Against the World: How Can Experiences Find Their Objects?" In John Searle's Philosophy of Language, edited by Savas Tsohatzidis, 64-78. Cambridge: Cambridge University Press.

Bayne, Tim. 2007. "The Unity of Consciousness: A Cartography." In Cartographies of the Mind: Philosophy and Psychology in Intersection, edited by Massimo Marraffa, Mario de Caro and Francesco Ferretti, 201-10. Dordrecht: Kluwer.

Blake, Randolph. 2001. "A Primer on Binocular Rivalry, Including Current Controversies." Brain and Mind 2: 5-38.

Braun, David. 1993. "Empty Names." Noûs 27: 449-69.

1998. "Understanding Belief Reports." Philosophical Review 107: $555-95$.

30 Thanks to David Braun, Todd Ganson, Adam Pautz, and Lewis Powell for comments or discussion that lead to significant improvements to this paper. 
2007. "Indexicals." In The Stanford Encyclopedia of Philosophy, edited by Edward Zalta. http://plato.stanford.edu/archives/sum2012/ entries/indexicals/.

Burge, Tyler. 1991. "Vision and Intentional Content." In John Searle and his Critics, edited by Ernest Lepore and Robert Van Gulick, 195-213. Cambridge, MA: Blackwell.

Byrne, Alex. 2009. "Experience and Content." Philosophical Quarterly 59: 429-51.

and Heather Logue. 2008. "Either/Or." In Disjunctivism: Perception, Action, Knowledge, edited by Adrian Haddock and Fiona Macpherson, 57-94. Oxford: Oxford University Press.

Chalmers, David. 2004. "The Representational Character of Experience." In The Future for Philosophy, edited by Brian Leiter, 153-81. Oxford: Clarendon Press.

. 2010. "Afterword: The Two-Dimensional Content of Perception." In

The Character of Consciousness, 372-79. New York: Oxford University Press.

2013. "The Contents of Consciousness: Reply to Hellie, Peacocke and Siegel." Analysis 73: 345-68.

Crane, Tim. 1988. "The Waterfall Illusion.” Analysis 48: 142-47.

Crimmins, Mark and John Perry. 1989. "The Prince and the Phone Booth: Reporting Puzzling Beliefs." Journal of Philosophy 86: 685-711.

Davies, Martin. 1992. "Perceptual Content and Local Supervenience." Proceedings of the Aristotelian Society 92: 21-45.

Engel, Andreas, Pascal Fries, and Wolf Singer. 2001. "Dynamic Predictions: Oscillations and Synchrony in Top-Down Processing." Nature Reviews Neuroscience 2: 704-16.

Guttman, Sharon and Philip Kellman. 2004. "Contour Interpolation Revealed by a Dot Localization Paradigm.” Vision Research 44: 1799-815.

Hellie, Benj. 2005. "Noise and Perceptual Indiscriminability." Mind 114: 481-508.

Knyazeva, Maria, Cristian Carmeli, Eleonora Fornari, Reto Meuli, Michael

Small, Richard Frackowiak, and Philippe Maeder. 2011. "Binding under

Conflict Conditions: State-Space Analysis of Multivariate EEG Synchronization." Journal of Cognitive Neuroscience 23: 2343-355.

Matey, Jennifer. 2012. "Representing the Impossible." Philosophical Psychology 26: 188-206.

Murray, Richard, Allison Sekuler, and Patrick Bennett. 2001. "Time Course of Amodal Completion Revealed by a Shape Discrimination Task." Psychonomic Bulletin \& Review 8: 713-20.

O'Callaghan, Casey. 2008. "Object Perception: Vision and Audition."

Philosophy Compass 3 4: 803-29.

Palmer, Stephen. 1999. Vision Science. Cambridge, MA: MIT Press. 
Pautz, Adam. 2009. "What are the Contents of Experiences?" Philosophical Quarterly 59: 483-507.

- 2010. "Why Explain Visual Experience in Terms of Content?" In Perceiving the World, edited by Bence Nanay, 254-309. Oxford: Oxford University Press.

Peacocke, Christopher. 1992. A Study of Concepts. Cambridge, MA: MIT Press.

Perry, John. 2001. Reference and Reflexivity. Stanford: CSLI Publications.

Peterson, Mary and Ruth Kimchi. 2013. "Perceptual Organization in Vision." In The Oxford Handbook of Cognitive Psychology, edited by Daniel Reisberg, 9-31. Oxford: Oxford University Press.

Rensink, Ronald and James Enns. 1998. "Early Completion of Occluded Objects." Vision Research 38: 2489-505.

Robertson, Lynn. 2003. "Binding, Spatial Attention, and Perceptual Awareness." Nature Reviews Neuroscience 4: 93-102.

Sainsbury, R. M. and Michael Tye. 2012. Seven Puzzles of Thought and How to Solve Them. Oxford: Oxford University Press.

Salmon, Nathan. 1986. Frege's Puzzle. Cambridge, MA: MIT Press.

Schellenberg, Susanna. 2010. "The Particularity and Phenomenology of Perceptual Experience." Philosophical Studies 149: 19-48.

Scholl, Brian. 2001. "Objects and Attention: the State of the Art." Cognition 80: 1-46.

Searle, John. 1983. Intentionality. Cambridge: Cambridge University Press.

Sekuler, Allison and Stephen Palmer. 1992. "Perception of Partly Occluded

Objects: a Microgenetic Analysis." Journal of Experimental Psychology: General 121: 95-111.

Shepard, Roger. 1990. Mind Sights. London: Palgrave.

Siegel, Susanna. 2010. The Contents of Visual Experience. Oxford: Oxford University Press.

- 2013. "Are There Edenic Grounds of Perceptual Intentionality?" Analysis 73: 329-44.

Soames, Scott. 1995. "Beyond Singular Propositions?" Canadian Journal of Philosophy 25: 515-50.

Soteriou, Matthew. 2000. "The Particularity of Visual Perception." European Journal of Philosophy 8: 173-89.

Speaks, Jeff. 2009. "Transparency, Intentionalism, and the Nature of Perceptual Content." Philosophy and Phenomenological Research 79: 539-73.

Thau, Michael. 2002. Consciousness and Cognition. Oxford: Oxford University Press.

Tononi, Giulio and Gerald Edelman. 1998. "Consciousness and Complexity." Science 282: 1846-51. 
Treisman, Anne. 1996. "The Binding Problem." Current Opinion in Neurobiology 6: 171-78.

Tye, Michael. 1995. Ten Problems of Consciousness. Cambridge, MA: MIT Press.

2000. Consciousness, Color, and Content. Cambridge, MA: MIT Press.

. 2007. "Intentionalism and the Argument from No Common Content." In Philosophical Perspectives 21: Philosophy of Mind, edited by John Hawthorne, 589-613. Malden, MA: Blackwell.

Uhlhaas, Peter, Gordon Pipa, Bruss Lima, Lucia Melloni, Sergio Neuenschwander, Danko Nikolić, and Wolf Singer. 2009. "Neural Synchrony in Cortical Networks: History, Concept and Current Status." Frontiers in Integrative Neuroscience 3: 1-19. 